Supporting Information

\title{
Bottom-up Approach Design, Band Structure and Lithium Storage Properties of Atomically Thin $\gamma$-FeOOH Nanosheets
}

\author{
Yun Song,,${ }^{\dagger}$ Yu Cao, ${ }^{\dagger}$ Jing Wang, ${ }^{\dagger}$ Yong-Ning Zhou, ${ }^{\dagger}$ Fang Fang, ${ }^{\dagger}$ Yuesheng Li,${ }^{\dagger}$ \\ Shang-Peng Gao, ${ }^{\dagger}$ Qin-Fen Gu, ${ }^{\ddagger}$ Linfeng Hu, ${ }^{\dagger}$ Dalin Sun $^{\dagger *}$
}

${ }^{\dagger}$ Department of Materials Science, Fudan University, Shanghai 200433, P. R. China

${ }^{*}$ Australia Synchrotron, 800 Blackburn Road, Clayton, 3168, Australia

*Corresponding author:dlsun@fudan.edu.cn 
Table S1. Structure parameters for $\gamma$-FeOOH (JCPDS card, No. 44-1415. $a=12.52$ $\AA, b=3.87 \AA, c=3.07 \AA)$ showing fractional coordinates $(x, y, z)$ and occupancies (g).

\begin{tabular}{ccccc}
\hline Atom & $x$ & $y$ & $z$ & $g$ \\
\hline $\mathrm{Fe}$ & 0.678 & 0.25 & 0 & 1 \\
$\mathrm{O}$ & 0.282 & 0.25 & 0 & 1 \\
$\mathrm{OH}$ & 0.075 & 0.25 & 0 & 1 \\
\hline
\end{tabular}




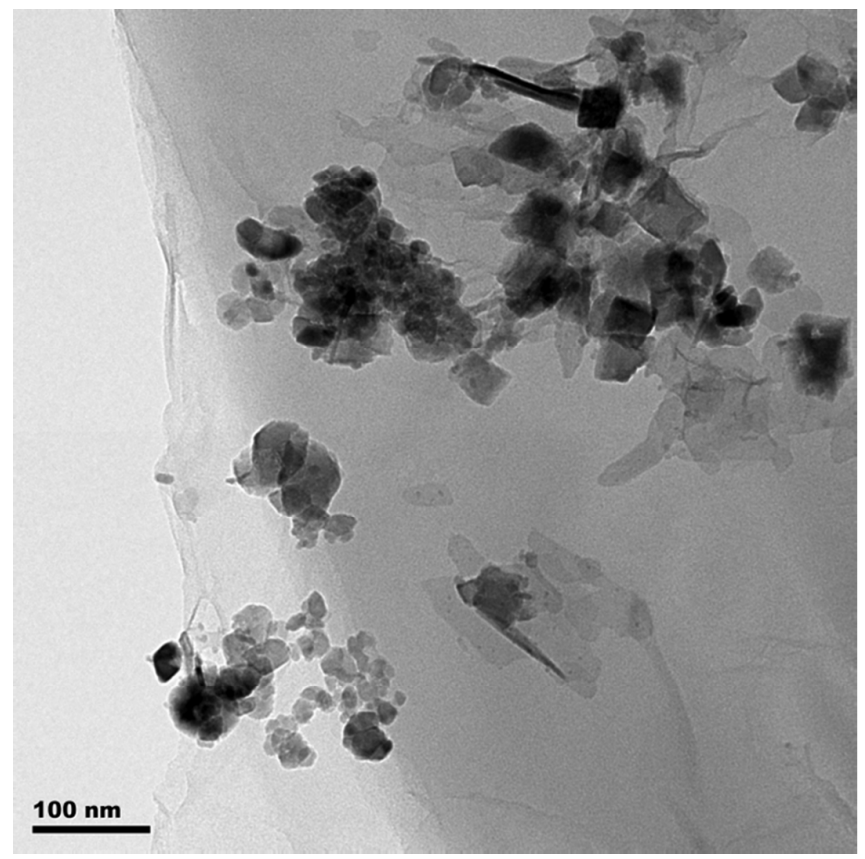

Figure S1. TEM image of the product synthesized at a high $\mathrm{FeCl}_{2}$ concentration of $0.6 \mathrm{~g} \mathrm{~L}^{-1}$. 


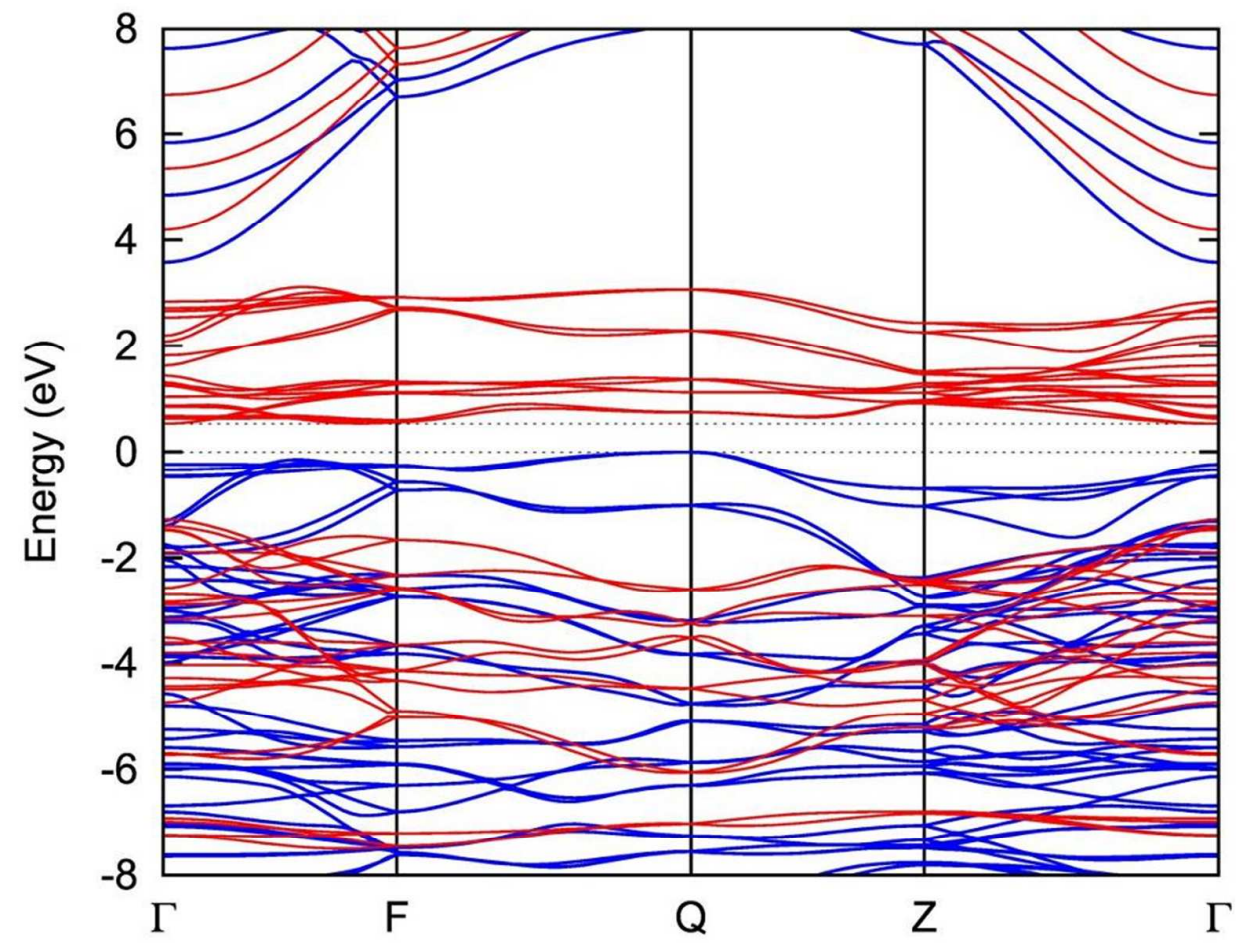

Figure S2. Band structure of $\gamma$-FeOOH 3D bulk. The Brillouin paths are chosen the same as that of $2 \mathrm{D} \gamma-\mathrm{FeOOH}$ nanosheet for a direct comparison. 


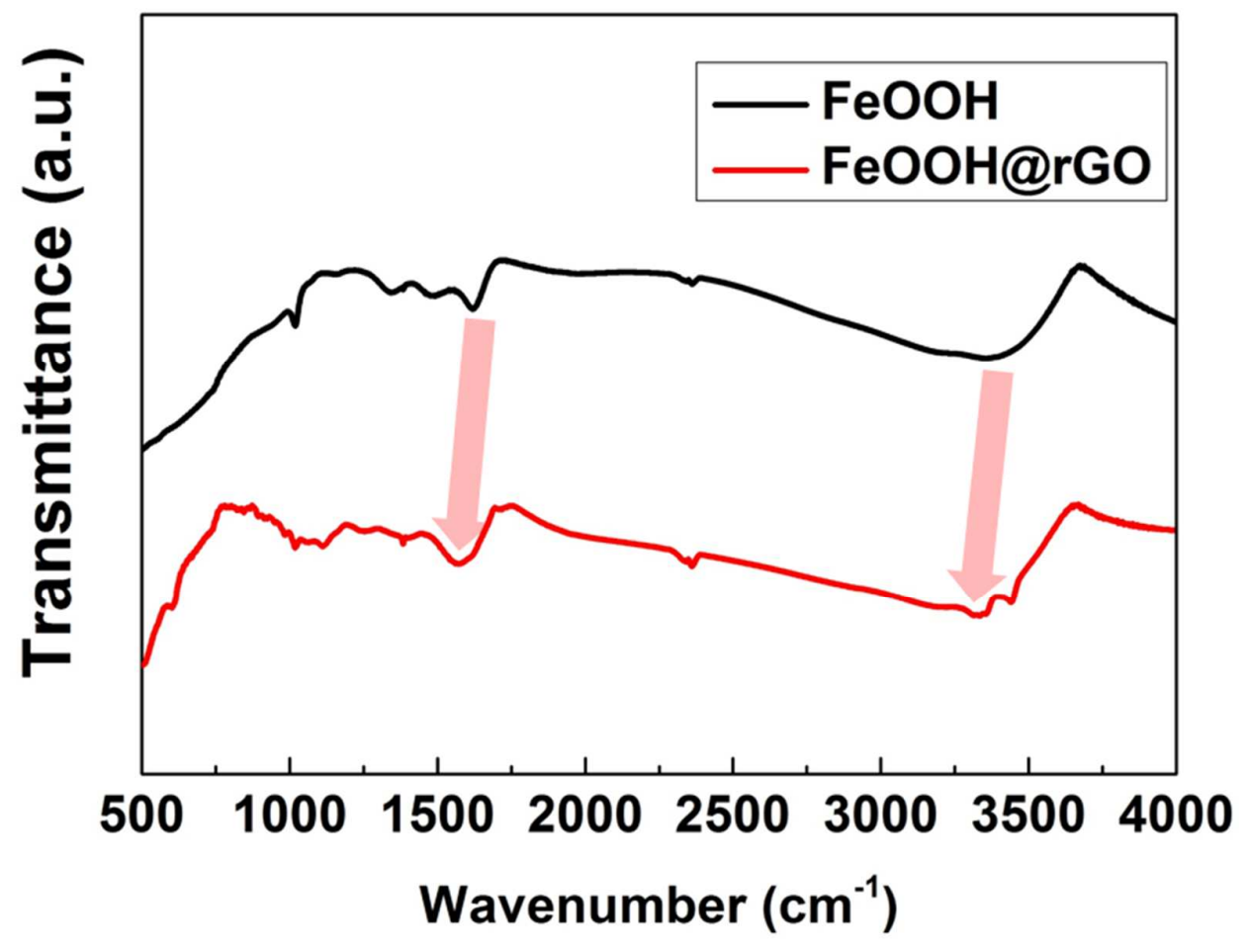

Fig. S3. FTIR spectra of FeOOH and FeOOH@rGO composite 

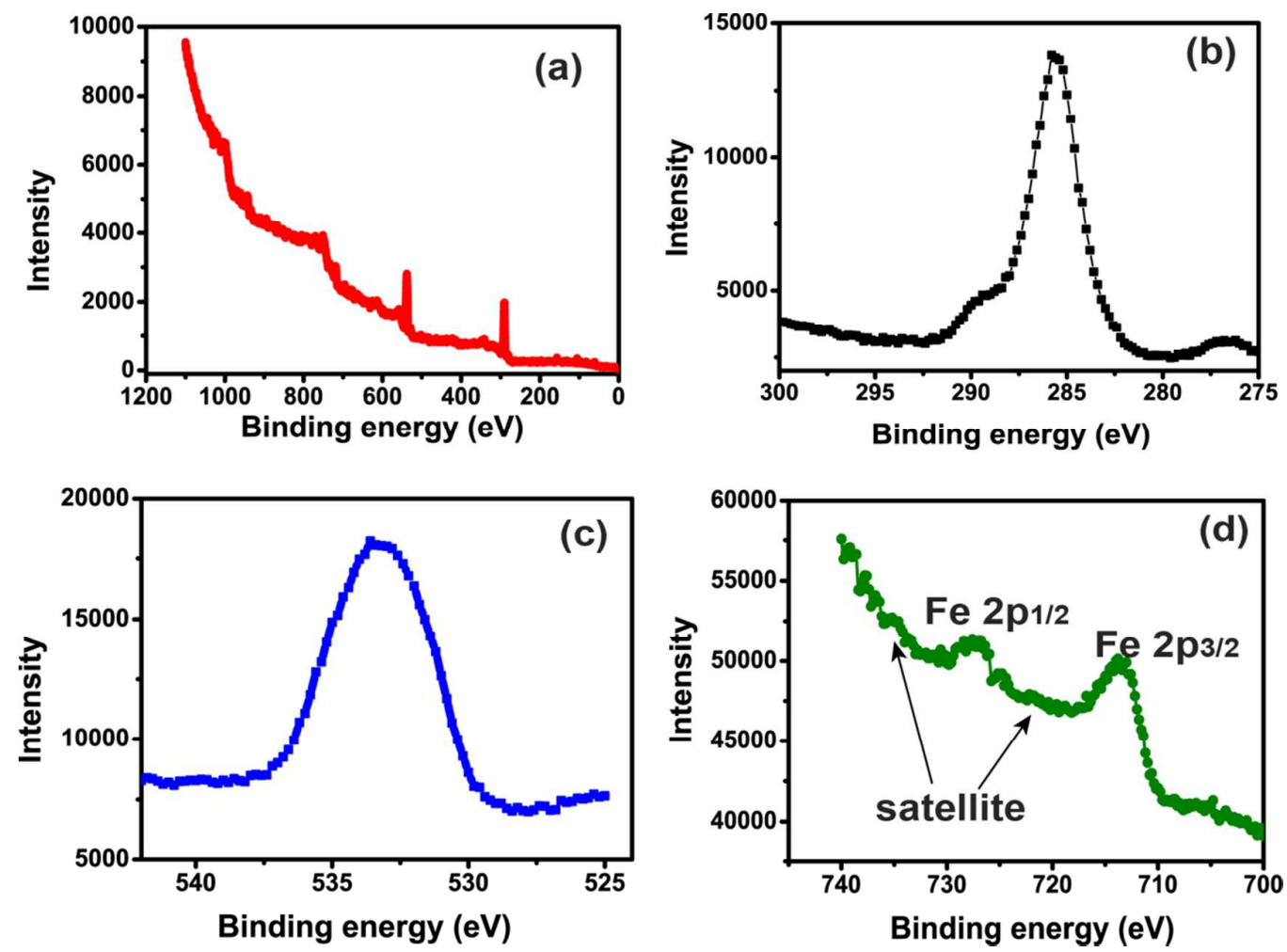

Figure S4. XPS spectra of (a) $\gamma-\mathrm{FeOOH}$ @rGO nanocomposites, (b-d) high resolution XPS spectra for C, O and Fe elements, respectively. Two peaks at 713.8 and $727.6 \mathrm{eV}$ can be assigned to $\mathrm{Fe} 2 \mathrm{p}_{3 / 2}$ and $\mathrm{Fe} 2 \mathrm{p}_{1 / 2}$ main peaks, respectively. The appearance of satellite bands near the Fe $2 p$ main peaks is generally regarded as an indicator of the valence state of $\mathrm{Fe}^{3+} .{ }^{[1]}$ In addition, The $\mathrm{C} 1 \mathrm{~s}$ spectrum of FeOOH@rGO nanocomposites can be resolved into two peaks centered at 284.5 and $287.8 \mathrm{eV}$, assigning to $\mathrm{C}-\mathrm{C}$ and $\mathrm{C}=\mathrm{O}$ bonds, respectively. The intensity of $\mathrm{C}-\mathrm{C}$ bond is much higher than that of $\mathrm{C}=\mathrm{O}$ bond, demonstrating the successful reduction of $\mathrm{GO}$ into $\mathrm{rGO}$ in our process. 


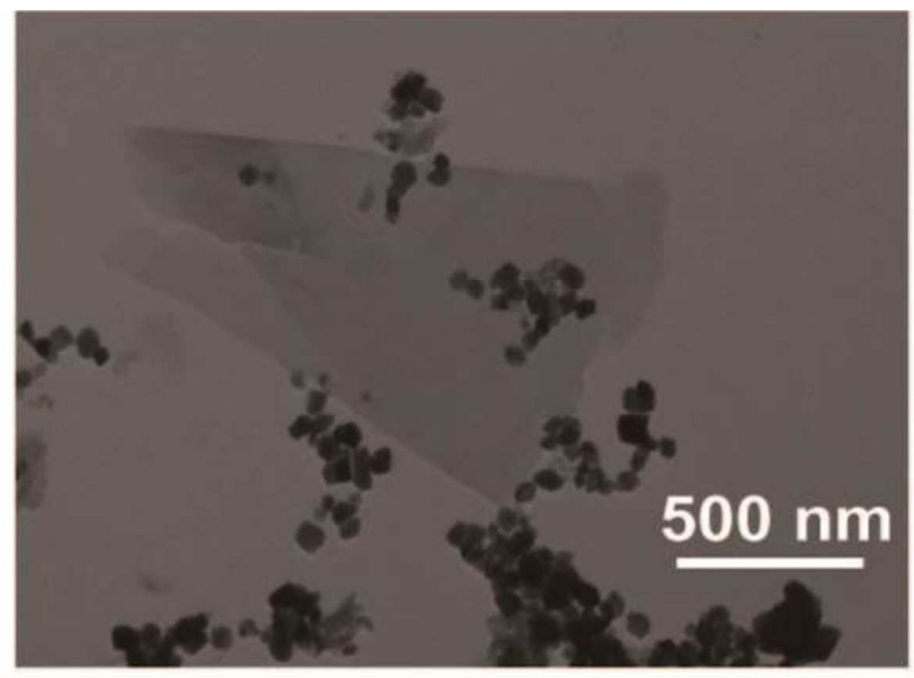

Figure S5. The TEM image of the sample prepared by mixing $\gamma$-FeOOH nanosheets and GO at a hydrothermal temperature of $170^{\circ} \mathrm{C}$. Higher hydrothermal temperature of $170{ }^{\circ} \mathrm{C}$ is disadvantageous for the homogenous dispersion of $\gamma$-FeOOH on rGO. 
Table S2. Comparison of the cycling stability of the as-obtained $\gamma-\mathrm{FeOOH} @ \mathrm{rGO}$ and previously reported FeOOH-based materials ( $>50$ cycles). This fast activation process of $\gamma$-FeOOH@rGO nanocomposites is superior to other reported FeOOH systems, which always suffer from longstanding activation process.

\begin{tabular}{|c|c|c|c|c|c|}
\hline Anode & $\begin{array}{l}\text { activation } \\
\text { cycle } \\
\text { number }\end{array}$ & $\begin{array}{c}\text { valley } \\
\text { capacity } \\
\left(\mathrm{mAh} \mathrm{g}^{-1}\right)\end{array}$ & $\begin{array}{c}\text { stable } \\
\text { capacity } \\
(\mathrm{mAh} \\
\left.\mathrm{g}^{-1}\right)\end{array}$ & $\begin{array}{l}\text { fluctuation } \\
\text { ratio }\end{array}$ & Ref \\
\hline $\begin{array}{c}\text { Mn-doped } \alpha \text {-FeOOH } \\
\text { nanorods }\end{array}$ & $\sim 200$ & $\sim 500$ & 883 & $\sim 43 \%$ & 2 \\
\hline$\beta$-FeOOH nanorods & $\sim 300$ & 285 & $\sim 500$ & $\sim 45 \%$ & 3 \\
\hline $\begin{array}{c}10 \text { wt. } \% \text { graphite } \\
\text { doped } \beta \text {-FeOOH } \\
\text { nanorods }\end{array}$ & $\sim 300$ & $\sim 300$ & $\sim 600$ & $\sim 50 \%$ & 3 \\
\hline $\begin{array}{c}\text { amorphous } \mathrm{FeOOH} \\
\text { particle/rGO }\end{array}$ & $\sim 100$ & $\sim 600$ & 767 & $\sim 21 \%$ & 4 \\
\hline $\begin{array}{c}\text { ultrathin } \gamma \text {-FeOOH } \\
\text { nanosheets@rGO }\end{array}$ & $\sim 10$ & 790 & 860 & $8 \%$ & $\begin{array}{l}\text { This } \\
\text { work }\end{array}$ \\
\hline
\end{tabular}




\section{REFERENCES}

(1) Ma, R.; Liang, J.; Takada, K.; Sasaki, T. Topochemical Synthesis of Co-Fe Layered Double Hydroxides at Varied Fe/Co Ratios: Unique Intercalation of Triiodide and Its Profound Effect. J. Am. Chem. Soc. 2011, 133, 613-620.

(2) Zhai, Y. J.; Ma, X. J.; Mao, H. Z.; Shao, W. W.; Xu, L. Q.; He, Y. Y. Mn-Doped Alpha-FeOOH Nanorods and Alpha- $\mathrm{Fe}_{2} \mathrm{O}_{3}$ Mesoporous Nanorods: Facile Synthesis and Applications as High Performance Anodes for LIBs. Adv. Electron. Mater. 2015, 1, 1400057.

(3) Yu, L. H.; Xi, S. B., Wei, C.; Zhang, W. Y.; Du, Y. H.; Yan, Q. Y.; Xu, Z. J. Superior Lithium Storage Properties of Beta-FeOOH. Adv. Energy Mater. 2015, 5, 1401517.

(4) Sun, Y.; Hu, X.; Luo, W.; Xu, H.; Hu, C.; Huang, Y. Synthesis of Amorphous FeOOH/Reduced Graphene Oxide Composite by Infrared Irradiation and Its Superior Lithium Storage Performance. ACS Appl. Mater. Interfaces 2013, 5, 10145-10150. 